\title{
Política monetária e ciclo financeiro global: uma análise sobre o caso brasileiro durante o regime de metas de inflação
}

\author{
Mateus Ramalho Ribeiro da Fonseca* \\ Pedro Perfeito da Silva ${ }^{+}$ \\ Eliane Cristina de Araújo ${ }^{\ddagger}$
}

\begin{abstract}
Resumo
O presente artigo investiga os desdobramentos de um aumento da taxa básica de juros sobre a estabilidade do nível de preços, o objetivo é avaliar a efetividade da política monetária no Brasil, no período entre 2000 e 2014, caracterizado pela vigência do Regime de Metas de Inflação (RMI). Nesse sentido, o estudo resgatou a crítica pós-keynesiana ao Novo Consenso Macroeconômico, bem como a discussão centrada nos impactos do ciclo financeiro global sobre países emergentes e em desenvolvimento. Em termos empíricos, a estimação do modelo de Vetores Autorregressivos com Correção de Erros (VEC) apresentou resultados alinhados com a literatura crítica ao RMI. Assim, a elevação da taxa de juros tem um impacto misto sobre a inflação. Por um lado, quando avaliada isoladamente, uma política monetária contracionista tem um efeito inicial inflacionário devido ao fenômeno do price-puzzle; por outro, um aumento da taxa de juros tende a gerar sobrevalorização cambial, a qual ajuda a conter a inflação. Além disso, a sobrevalorização cambial também se relaciona à ascensão do ciclo financeiro global, facilitando o cumprimento da meta durante o período analisado.
\end{abstract}

Palavras-chave: regime de metas de inflação, ciclo financeiro global, Brasil.

\begin{abstract}
The present article investigates the consequences of an increase in the benchmark interest rate on price level stability. The objective is to evaluate the Brazilian monetary policy for the period between 2000 and 2014, characterized by the Inflation Target Regime (ITR). Regarding this, the study considers the post-Keynesian critique to the New Macroeconomic Consensus, as well as the discussion centered on the impacts of the global financial cycle on emerging and developing countries. In empirical terms, the estimation of the Error Correction Autoregressive Vectors model (VEC) presents results in line with the critical literature about ITR. Thus, a rise in the interest rate has a mixed impact on inflation rate. On the one hand, a contractionary monetary policy has an initial inflationary effect due to the price-puzzle phenomenon; on the other hand, an increase in interest rates tends to generate currency overvaluation, which helps to contain inflation. In addition, a currency overvaluation is also related to the rise of the global financial cycle, facilitating the achievement of the target during periods.
\end{abstract}

Keywords: inflation target regime, global financial cycle, Brazil.

JEL Classification: C14, E12, E42.

\footnotetext{
"Doutorando no Programa de Pós-Graduação em Economia da Universidade Federal do Rio Grande do Sul. Bolsista CAPES. Email: mateusramalho88@hotmail.com

${ }^{\dagger}$ Doutorando no Programa de Pós-Graduação em Economia da Universidade Federal do Rio Grande do Sul. Bolsista CAPES. Email: pperfeitodasilva@gmail.com

${ }^{\ddagger}$ Professora da Universidade Estadual de Maringá e pesquisadora do CNPq. Email: elianedearaujo@gmail.com
} 


\section{Introdução}

A crise do Sistema de Bretton Woods (SBW), no começo da década de 1970, engendrou mudanças no Sistema Monetário e Financeiro Internacional (SMFI), bem como na formulação da política econômica doméstica, em especial, para economias emergentes e em desenvolvimento. No âmbito externo, os países deveriam perseguir a liberalização das relações econômicas tanto na dimensão comercial quanto na financeira, aproveitando a entrada de capitais e a disciplina do comércio internacional sobre as políticas governamentais. Internamente, o foco passaria a ser o controle da inflação, o qual, junto a regras claras, impulsionaria a confiança do setor privado, verdadeiro protagonista do processo de crescimento.

Com a derrocada do Estado Desenvolvimentista no começo da década de 1980, o Brasil aderiu a uma estratégia de inserção subordinada na globalização, principalmente, pela via financeira. Dessa maneira, nas relações econômicas com o resto do mundo, instituiu-se um processo pragmático, mas ascendente de liberalização comercial e financeira, enquanto, internamente, reduziu-se o escopo da intervenção estatal, priorizando a estabilização do nível de preços.

Se, por um lado, isso possibilitou a superação da hiperinflação, com o Plano Real (1994), por outro, uma estratégia de crescimento via poupança externa, combinada ao regime cambial fixo engendrou novas formas de instabilidade, culminando na crise financeira de 1999. Em resposta a isso, a política macroeconômica brasileira aderiu ao chamado tripé macroeconômico, baseado no regime cambial flexível, em uma meta de superávit primário e no regime de meta inflacionária (RMI), a ser cumprida por meio de um instrumento principal, a manipulação da taxa básica de juros.

Ao longo de quase duas décadas de vigência do RMI, diversos estudos como Sicsú (2002), Mendonça (2004, 2005, 2007), Minella et al. (2003), Squeff (2009), Ferreira e Jayme Jr (2005), Dezordi et al. (2009), Mendonça, Dezordi e Curado (2009), Modenesi e Araújo (2011, 2013) e Fonseca, Oreiro e Araújo (2017) avaliaram a relação entre taxa básica de juros e inflação no caso brasileiro, problematizando a efetividade de um aumento na taxa de juros para a promoção da estabilidade do nível de preços. Não obstante, esses trabalhos não incluem o ciclo financeiro global como uma variável de interesse, a qual tem desdobramentos relevantes quanto à evolução da taxa de inflação, posto que afeta a autonomia e a efetividade da política monetária em questão.

Tendo isso em vista, o presente artigo pretende avaliara relação entre a taxa básica de juros e o nível geral de preços para o caso do regime brasileiro de metas inflacionárias. Com esse objetivo principal, estima-se um modelo de vetores autorregressivos com correção de erros (VEC), baseado no modelo de Modenesi e Araújo (2013), a partir de uma amostra mensal que vai de janeiro de 2000 a dezembro de 2014. Adicionalmente, sendo esta uma contribuição potencialmente original, a estimação considera também aspectos como o ciclo financeiro global.

Parte-se do argumento principal de que a elevação da taxa de juros tem um impacto misto sobre a inflação. Por um lado, quando avaliada isoladamente, uma política monetária contracionista pode ter um efeito positivo sobre o nível de preços devido ao fenômeno do price-puzzle; por outro, um aumento da taxa de juros posse associado a um processo de sobrevalorização cambial, a qual ajuda a conter a inflação.

Além disso, também se considera a hipótese de que a sobrevalorização cambial responde à evolução do ciclo financeiro global. Nesse sentido, observa-se uma tendência à 
redução da taxa de câmbio em economias emergentes como a brasileira em períodos de ascensão do ciclo, facilitando o cumprimento da meta durante tais períodos.

No que tange à organização do presente estudo, além dessa introdução, a próxima seção apresenta uma revisão da literatura teórica, seguida por uma breve exposição acerca literatura empírica focada no RMI. Após isso, as seções seguintes focam-se na estimação do exercício econométrico e na análise dos resultados. Por fim, são apresentadas as considerações finais.

\section{Novo Consenso Macroeconômico, Regime de Metas de Inflação e Ciclo Financeiro Global: uma crítica pós-keynesiana}

\subsection{Arcabouço Teórico do Novo Consenso Macroeconômico}

A política macroeconômica sob o RMI parte do arcabouço teórico do Novo Consenso Macroeconômico (NCM), tendo sua origem no paradigma Novo-Clássico

*. Segundo Arestis e Sawyer (2002a, 2002b, 2008b) e Angeriz e Arestis (2007a) o NCM pode ser descrito, como segue, por seis equações ${ }^{\dagger}$ :

$$
\begin{aligned}
& Y_{t}^{g}=a_{0}+a_{1} Y_{t-1}^{g}+a_{2} E_{t}\left(Y_{t+1}^{g}\right)+a_{3}\left[R_{t}-E_{t}\left(p_{t+1}\right)\right]+a_{4} r e r_{t}+s_{1} \\
& p_{t}=b_{1} Y_{t}^{g}+b_{2} p_{t-1}+b_{3} E_{t}\left(p_{t+1}\right)+b_{4}\left[E_{t}\left(p_{w t+1}\right)-E_{t} \Delta e r_{t}\right]+s_{2} \\
& R_{t}=\left(1-c_{3}\right)\left[R R^{*}+E_{t}\left(p_{t+1}\right)+c_{1} Y_{t-1}^{g}+c_{2}\left(p_{t-1}-p^{T}\right)\right]+c_{3} R_{t-1}+s_{3} \\
& r e r_{t}=d_{0}+d_{1}\left[\left[R_{t}-E_{t}\left(p_{t+1}\right)\right]-\left[R_{w t}-E\left(p_{w t+1}\right)\right]\right]+d_{2} C A_{t}+d_{3} E_{t}\left(r e r_{t+1}\right)+s_{4} \\
& C A_{t}=e_{0}+e_{1} r e r_{t}+e_{2} Y_{t}^{g}+e_{3} Y_{w t}^{g}+s_{5} \\
& \operatorname{er}_{t}=\operatorname{rer}_{t}+P_{w t}-P_{t}
\end{aligned}
$$

As equações (1), (2) e (3) representam o modelo de regime monetário de metas de inflação, enquanto que as equações (4), (5) e (6) dizem respeito à macroeconomia aberta do modelo. Dessa maneira, o modelo possui seis equações para seis incógnitas: hiato do produto, taxa de juros, inflação, saldo em transações correntes, taxa de câmbio real e nominal. Com base nisso, muitos bancos centrais tomam decisões de política monetária (ARESTIS, SAWYER; 2002a, 2002b).

Duas considerações adicionais devem ser feitas acerca do exposto acima. Em primeiro lugar, considerando a política monetária, as equações (2) e (3) representam o funcionamento do RMI e sua operacionalização por parte da autoridade monetária, núcleo do estudo aqui proposto. Em segundo lugar, tal modelo não considera o ciclo financeiro global e seus efeitos. Nas próximas duas subseções, serão discutidas as críticas pós-keynesianas ao modelo do NCM e, em especial, ao RMI; bem como, o impacto do ciclo financeiro global sobre o funcionamento da política monetária.

\footnotetext{
* Para uma avaliação crítica dos paradigmas monetarista, novo-clássico, novo-keynesiano e póskeynesiano, ver Ferrari Filho (1996).

${ }^{\dagger}$ Sendo que $b_{2}+b_{3}=1, Y_{t}^{g}$ é o hiato do produto; $R$ corresponde à taxa nominal de juros; $p$ é a taxa de inflação vigente; $p^{T}$ é a meta de inflação; $R R^{*}$ é a taxa de juros real de equilíbrio, supondo que o crescimento do produto seja zero, a taxa de inflação é constante como mostra a equação (2); $s_{i}$ (sendo i $=1,2,3,4$ e 5) representa os choques estocásticos; e $E_{t}$ refere-se às expectativas no período $t$. $r e r_{t}$ (equação 4) representa a taxa de câmbio real da economia, enquanto $e r_{t}$ é a taxa nominal de câmbio (equação 5). $C A_{t}$ é o saldo em transações correntes da balança de pagamentos (equação 5).
} 


\subsection{Críticas Pós-Keynesianas ao NCM e ao RMI}

A crítica pós-keynesiana ao Novo Consenso Macroeconômico (NCM) reside, fundamentalmente, no tratamento dado à moeda. Segundo as correntes novo-clássica e novokeynesiana, partidárias do NCM e do RMI, a moeda é neutra no longo prazo. Por outro lado, Keynes (1976) afirma que, em uma economia monetária de produção, a moeda não é neutra, nem no curto e nem no longo prazo. Do ponto de vista teórico, Fontana (2006), nos termos de Arestis e Sawyer (2008a, 2008b) e Arestis (2009), destacou um aspecto diferente: um enfoque na rejeição da Teoria Quantitativa da Moeda por parte dos teóricos do mainstream ${ }^{\ddagger}$ e um retorno à posição Wickseliana de controle dos níveis de inflação por meio da utilização da taxa nominal de juros. Dessa forma, Fontana (2006) centra-se nos seguintes aspectos: i) os instrumentos de política monetária utilizados pelos bancos centrais; e ii) as variáveis macroeconômicas são afetadas no curto e no longo prazo neste processo. Como resultado, a grande maioria dos Bancos Centrais utiliza a taxa de juros como principal instrumento de política monetária, bem como a variável afetada é geralmente o nível de endividamento.

Com base nesses argumentos, Arestis (2009) observa que a adoção de uma âncora nominal, como ocorre no RMI, não deixa espaço para a estabilização do produto. A âncora nominal mais utilizada no regime de metas é a taxa básica de juros. Por se preocupar apenas com essa âncora, a autoridade monetária relega variáveis relevantes ao segundo plano, dentre as quais câmbio, emprego e crescimento do produto. Tal visão restrita torna a economia muito suscetível a flutuações. Para contornar esse problema, Bernanke (2003) e Meyer (2001) sugerem que a política monetária deveria se concentrar tanto no hiato de produção quanto na estabilidade de preços. Vale notar que o emprego da taxa de juros como uma única ferramenta de controle da inflação insere-se na controvérsia acercado próprio conceito de taxa de juros, em especial, da taxa de juros natural, presente na obra do Keynes (1973). Embora o autor não explicite a relação entre a taxa natural de juros e a taxa de mercado nas equações fundamentais, ela é um elemento central, uma vez que determina a igualdade entre poupança e investimento, os patamares de preços e o produto de uma economia. Segundo Keynes (1973, p. 139):

"Following Wicksell, it will be convenient to call the rate of interest which would cause the second term of our second fundamental equation to be zero the natural rate of interest, and the rate which actually prevails the market rate of interest. Thus the natural rate of interest is the rate at which saving and the value of investment are exactly balanced, so that the price level of output as a whole $(\pi)$ exactly corresponds to the money rate of efficient earnings of the factors of production. Every departure of the market rate from the natural tends, on the other hand, to set up a disturbance of the price level by causing the second term of the second fundamental equation to depart from zero".

Todavia, posteriormente, Keynes (1982) admite ser um equívoco tratar de maneira separada a taxa natural de juros e o volume de emprego. Dado que existem equilíbrios na ausência de pleno emprego, há que se tratar de múltiplas taxas de juros de equilíbrio: uma para determinar cada ponto de emprego dos fatores de produção, bem como uma taxa de juros dita ótima, que se refere ao pleno emprego. Em suas palavras:

"Em minha obra Treatise on Money defini o que pretendia ser uma taxa de juros de
natureza única, a que chamei de taxa natural de juros - isto é, aquela que na terminologia
de meu Treatise mantinha a igualdade entre o montante de poupança (segundo a definição
ali adotada) e o montante do investimento. Pensei assim desenvolver e esclarecer a noção
de "taxa natural de juros" de Wicksell que, segundo ele, era a que conservaria a estabilidade
de um certo nível de preços não muito bem definida. (...) Tinha eu, contudo, ignorado o fato
de que, segundo esta definição, há em cada sociedade uma taxa de juros diferente para

‡ Para uma discussão a respeito do conceito de mainstream, ver Colander (2000). 
cada volume teórico de emprego hipotético. E para ele a mesma é "natural" no sentido de que o sistema estará em equilíbrio com esse nível de taxa de juros e esse volume de emprego. Foi, portanto, um erro falar da taxa natural de juros ou sugerir que anterior definição the daria um valor único independente do volume de emprego. Eu não compreendera então que, em certas circunstâncias, o sistema pode estar em equilíbrio abaixo do pleno emprego" (Keynes, 1982, p. 189).

Após as considerações teóricas acerca da crítica pós-keynesiana, faz-se necessário analisar os limites empírico do NCM. Em primeiro lugar, os estudos de Sicsú (2003), Arestis e Sawyer (2003) e Modenesi (2005) apontam que não há correlação entre a adoção do RMI e a queda da taxa de inflação. Nesse sentido, Modenesi (2005) mostra que países que não adotaram o RMI também tiveram êxito no controle inflacionário a partir da década de 1990, assim como os relatórios do Banco de Compensações Internacionais (BIS; 2014, 2015) sublinham o papel da ascensão do ciclo financeiro global na edificação da chamada Grande Moderação, caracterizada pelas baixas taxas de inflação ao redor do mundo.

Com o intuito de organizar os limites decorrentes da aplicação do NCM e do RMI, segue-se a organização apresentada por Arestis (2009). Nesse estudo, o autor expõe os oito aspectos fundamentais: i) a baixa inflação e a estabilidade de preços nem sempre levam a estabilidade econômica; ii) a taxa de câmbio recebe pouca atenção na formulação das políticas econômicas; iii) não há evidências suficientes de que a curva de Phillips seja vertical no longo prazo quando as taxas de juros são baixas; iv) não há provas de que a NAIRU ${ }^{\S}$ não é afetada pelas políticas econômicas, pela demanda agregada e pela existência de mercados de trabalho flexíveis; v) países que não adotaram o regime de metas de inflação têm obtido bons resultados no controle inflacionário, tanto quanto aqueles países que adotaram o regime; vi) não há evidências empíricas de que uma política fiscal contracionista realmente afete o nível de preços; vii) não se tem evidências de que as proposições teóricas do NCM sejam validadas pela evidência empírica disponível; e, por último, viii) o regime de metas de inflação é eficiente para combater processos inflacionários oriundos de pressões de demanda, mas isso não se aplica à inflação de custos.

No que diz respeito ao primeiro argumento, Angeriz e Arestis $(2007 \mathrm{~b}, 2008)$ mostram que o modelo do NCM é caracterizado por uma política monetária na qual a taxa de juros é o instrumento básico, sem menção ao mercado monetário e às instituições financeiras. Ou seja, os modelos de política monetária ignoram completamente o fato de existir um mercado bancário, com capacidade de criação de moeda, e um mercado financeiro propenso a inovações. Isso gera distorções de caráter monetário, implicando em estimações equivocadas, principalmente, nos países emergentes. Sublinha-se também que o paradigma pós-keynesiano assenta-se na não-neutralidade da moeda, isto é, no fato de que a política monetária tem um efeito persistente sobre as variáveis reais da economia. Tal aspecto pode ser ilustrado pela seguinte passagem:

“[...] em uma economia empresarial, os indivíduos, em determinadas situações, preferem reter moeda ao invés de demandar por ativos reprodutíveis, resultando em uma diminuição do nível de atividade econômica. Em outras palavras, a moeda, devido a alguns atributos peculiares (leia-se elevado prêmio de liquidez), torna-se especialmente atraente em certas conjunturas, o que leva a uma realocação da riqueza na direção dos ativos líquidos e uma transferência da circulação industrial para a circulação financeira" (Araújo, 2013, p. 08).

\footnotetext{
${ }^{\S}$ Acrônimo que significa Non-Accelerating Inflation Rate of Unemployment ou em português que significa taxa de desemprego não aceleradora da inflação. Para maiores informações ver Staiger, Stock e Watson (1997).
} 
Quanto à segunda crítica, ainda que haja equações sobre câmbio real e nominal (equações 4 e 6) e saldo em transações correntes (5), o NCM não define uma política cambial, recomendando sua ausência por meio do estabelecimento de um regime cambial flexível. Isso implica que o câmbio não é tratado como fundamental para determinação da taxa de inflação. Nesse ponto, há de se fazer duas considerações: uma, referente ao crescimento econômico, e outra a respeito do nível de preços.

Na primeira, conforme mostram Kaldor (1988), Oreiro, Nakabashi e Souza (2010) e Oreiro (2012), a demanda agregada é o motor de crescimento das economias capitalistas, sendo constituída por dois componentes: a demanda induzida e a demanda autônoma. A demanda induzida se estabelece em função do nível de produção e da renda, enquanto que a demanda autônoma independe do nível destes. No longo prazo, entretanto, é a demanda autônoma que determina a taxa de crescimento do produto, sendo constituída pelos gastos do governo e pelas exportações,no caso das economias abertas. Dada a insustentabilidade do déficit público no longo prazo, autores como Kaldor (1988), Ledesma (2002), Bresser-Pereira $(2006,2012)$ e Oreiro (2012) advogam um regime de crescimento liderado pelas exportações (export-led growth), no qual a taxa de câmbio se torna uma variável estratégica para o crescimento econômico sustentável no longo prazo. Tal abordagem aponta a necessidade de um câmbio desvalorizado e administrado de forma a manter o saldo em transações correntes maior ou igual zero, proporcionando um ambiente competitivo e proporcionar ao setor industrial nacional frente às concorrentes estrangeiras.

No que tange ao nível de preços de economias abertas, Squeff (2009) e Modenesi e Araujo $(2011,2013)$ observam que mudanças no câmbio têm apresentado efeitos significativos e persistentes sobre a inflação brasileira, não podendo ser desconsiderada na avaliação da política monetária. Nesse sentido, tais estudos encontraram evidências empíricas de que oscilações cambiais impactam diretamente no nível de preços da economia brasileira, de modo que o câmbio teria sido usado em meados dos anos 2000 como uma ferramenta de controle inflacionário.

Passando à terceira crítica ao RMI, Hallett (2000) alerta a ausência de evidencias empíricas suficientes para afirmar que a curva de Phillips é vertical no longo prazo. A interpretação de tal variável opõe duas correntes teóricas: i) a primeira afirma que a curva de Phillips é vertical no longo prazo, de forma que mudanças de curto prazo, por quaisquer motivos, geram inflação; e ii) a segunda defende que não há evidências concretas de que a curva de Phillips seja vertical, quando se opera com baixos níveis de inflação. Em linha com a segunda abordagem, Jucelius (2008) apresenta evidências empíricas, com base em dados existentes para os Estados Unidos e para a Zona do Euro, de que mudanças em variáveis nominais (como a moeda) impactam variáveis reais (como o produto).

Arestis, Baddeley e Sawyer (2007) e Arestis e Sawyer (2006) discutem sobre o impacto da taxa de desemprego na inflação. Para tais autores, mudanças na demanda agregada e nos mercados de trabalhos ditos flexíveis tendem a impactar o nível de emprego. Por exemplo, uma política fiscal expansionista (via renúncia fiscal e/ou aumentos dos gastos) tende a expandir a demanda agregada, diminuindo a taxa de desemprego. Esse resultado foi verificado pelos autores para nove países da União Europeia. Ou seja, uma mudança na demanda agregada teve impacto significativo no nível de emprego em países com mercados de trabalhos ditos flexíveis.

No quinto argumento, já discutido no início desta subseção, Angeriz e Arestis (2007a, 2008) e Arestis, Ferrari Filho e Paula $(2007,2011)$ notam que o RMI foi efetivo no sentido do controle inflacionário, inclusive no Brasil. No entanto, o mesmo resultado foi observado para países que não aderiram ao RMI. No mundo todo, a inflação se desacelerou no início da 
década de 1990. Isso significa que parte do sucesso do controle inflacionário não está relacionada ao regime monetário em si, mas por outras questões, como queda generalizada dos níveis de preços em todo o mundo, aumento de produtividade e ascensão do ciclo financeiro global, o qual facilita o controle da inflação em países que experimentaram processos de valorização cambial associada a influxos excessivos de capitais de curto prazo.

No sexto tópico, Angeriz e Arestis (2009) discutem o fato de que a política monetária envolve basicamente a manipulação da taxa de juros do Banco Central para alcançar o seu objetivo principal, que na maioria das vezes, é o controle da taxa de inflação. Além disso, mudanças na política fiscal são lentas quando comparadas com mudanças na política monetária, fazendo com que a primeira política seja eficiente para a estabilização do produto. Os autores realizaram um estudo para a Zona do Euro, EUA e Reino Unidos, no qual o objetivo era medir a sensibilidade da inflação a mudanças na taxa de juros e se essas mudanças impactariam variáveis reais. Como resultado, destaca-se que: i) os resultados empíricos apontam para um efeito relativamente fraco das alterações da taxa de juros sobre a inflação; e que ii) a política monetária pode ter efeitos de longo prazo sobre variáveis reais. Nessa mesma linha, Hein e Truger (2008) e Hein e Schoder (2011) abordam o mix de políticas fiscal e monetária, comparando os quadros de França, Alemanha, Inglaterra e Suécia. Os autores chegaram a resultados semelhantes ao de Angeriz e Arestis (2009), concluindo que não há evidência de que a política monetária expansionista impacta positivamente a inflação, bem como que a política fiscal contracionista tem desdobramentos negativos sobre a inflação.

Os estudos de Walsh (2003) e Modenesi e Araujo (2011 e 2013) e Fonseca, Oreiro e Araújo (2017) apontam a existência de prize puzzle ${ }^{* *}$ na política monetária de maneira geral e para a economia brasileira, respectivamente. Tal fenômeno ocorre quando a taxa de juros e a inflação tem uma relação positiva, isto é, quando um aumento na taxa de juros, ao invés de reduzir, gera uma elevação na taxa de inflação. A literatura empírica que busca uma solução para o price puzzle é formada por dois grupos distintos. Para o primeiro, esse comportamento seria fruto de problemas de má identificação na estimação dos modelos VAR, isto é, as variáveis incluídas nos modelos estimados não esgotariam o conjunto de informações que o Banco Central teria a sua disposição (Sims, 1992). Por sua vez, o segundo grupo questiona a teoria convencional, associando o fenômeno a outro canal de transmissão da política monetária, o canal de custos ${ }^{\dagger \dagger}$, que operaria através da oferta agregada. Dessa forma, o price puzzle surgiria de um descompasso de uma política monetária contracionista sobre os custos de produção, que tem efeitos imediatos, via remarcação de preços, ao contrário dos efeitos defasados sobre a demanda agregada.

Na sétima crítica, Arestis e Sawyer (2004, 2008a, 2008b) afirmam que não há evidências suficientes que comprovem a validade empírica das proposições teóricas do NCM. Vale notar que os estudos expostos na presente e na próxima seção dão suporte à sétima critica pós-keynesiana. Por último, Arestis e Sawyer (2009) argumentam que a política do RMI tem como pretensão atacar apenas problemas inflacionários de demanda e não aqueles puxados pelos outros tipos de inflação já constatados teoricamente. Tal limitação, como mostram Sicsú (2003) e Modenesi (2005), força a autoridade monetária a usar excessivamente

\footnotetext{
** O ponto de partida para o estudo desse fenômeno é o artigo de Sims (1992), embora o termo "price puzzle" só tenha sido cunhado posteriormente por Eichenbaum (1992).

${ }^{++}$Resumidamente, esse canal opera da seguinte forma: um aumento da taxa de juros elevaria os custos de produção das firmas que, dependendo de seu poder de mercado e das condições de demanda, repassam o aumento aos preços praticados. Em um momento posterior, a elevação dos juros desaquece a economia, fazendo com que a demanda agregada diminua, impactando negativamente a inflação. Para maiores informações, ver Marques e Fochezatto (2006).
} 
um único instrumento de política monetária no controle inflacionário, prejudicando o desempenho econômico.

Com a Crise Financeira Global de 2007-2008 (CFG), todos esses aspectos se tornaram latentes, afinal, o receituário assentado no NCM e no RMI não garantiu uma identidade entre estabilização do nível de preços e estabilidade macroeconômica, principalmente ao se considerar a dimensão financeira dessa estabilidade. Portanto, a realidade forçou mudanças drásticas na condução das políticas econômicas, principalmente, na política monetária.

\subsection{O ciclo financeiro global e seus impactos sobre a política monetária}

Com a erupção da CFG, a política monetária expansionista e não convencional por parte dos Estados Unidos fortaleceu a discussão acerca do ciclo financeiro global e seus desdobramentos nos países que não possuem moeda conversível de fato e, portanto, tomam o ciclo. Destaca-se também que a literatura recente sobre o ciclo financeiro global remonta à preocupação de Minsky $(1986,1991)$ com a forma pela qual a interação entre as unidades produtivas, ligadas por compromissos de pagamento em um ambiente institucional específico, leva à evolução dos perfis de financiamento entre hedge, especulativo e Ponzi.

Os trabalhos recentes no âmbito do Banco de Compensações Internacionais (BIS) partem da reflexão acerca do ciclo financeiro global para encarar os desafios colocados pela Crise Financeira Global e seus desdobramentos. Nesse sentido, BIS (2014) e Borio (2012) conceituam o ciclo financeiro enquanto interações, mutuamente reforçadas, entre percepções sobre valor e risco, atitudes frente ao risco e constrangimentos financeiros. Destacam-se quatro características do ciclo financeiro: i) uma duração mais longa do que o ciclo de negócios; ii) a coincidência dos picos deste com crises bancárias; iii) a sincronização entre as economias, devido à mobilidade de capitais e ao papel do dólar; e iv) a resposta ao ambiente macroeconômico e ao regime de política econômica, de modo que a liberalização financeira e o Novo Consenso Macroeconômico elevaram a amplitude e a duração do ciclo.

Em termos empíricos, a mensuração do ciclo financeiro (doméstico ou global) pode ser feita a partir de diversas variáveis, sendo que o menor conjunto destas é composto pelo crescimento real do crédito, pela razão entre crédito e produto nominal e pelo crescimento real do preço dos imóveis. Os dois primeiros são uma proxy do grau de alavancagem, enquanto o último mede as garantias disponíveis. Dessa forma, a fase ascendente do ciclo é caracterizada pela expansão nessas dimensões. Trabalhos mais empíricos - como o de Nier, Sedik e Mondino (2014), Pasricha et al. (2015) e Rey (2013) - utilizam o indicador de volatilidade do mercado financeiro global (VIX), calculado pelo CBOE (Chicago Board Options Exchange Market). Um nível baixo do VIX caracteriza momentos de ascensão do ciclo financeiro global.

A abordagem baseada no ciclo financeiro global traz argumentos relevantes para a compreensão dos processos que levaram e decorreram da Crise Financeira Global. O primeiro deles é fruto da contribuição de Borio (2014) e Borio, James e Shin (2014) referente à fonte dos desequilíbrios no sistema financeiro e monetário internacional. Para os autores, a principal origem da instabilidade financeira seria a excessiva elasticidade desse sistema, materializada no fato de que a própria gestação de um período de ascensão cíclica leva a interações entre regimes institucionais e comportamentos dos agentes, as quais se reforçam mutuamente no sentido de aprofundar a trajetória expansiva, ampliando as vulnerabilidades nos setores financeiro e real da economia.

Segundo Borio (2014), a gestação de booms financeiros, que precede processos como a Crise Financeira Global, passa por diversos elementos. São eles: i) o caráter pró-cíclico e volátil das percepções de valor e risco por parte dos agentes, de modo que uma menor 
percepção de risco valida a valorização dos ativos, encorajando ainda mais a tomada de risco; ii) os incentivos inadequados aos agentes, reforçando o foco no curto prazo e problemas de coordenação e de agente-principal; iii) os mecanismos de reforço mútuo, como é o caso da interação entre a queda do risco percebido e o incentivo a tomar mais risco, dado que se observa um aumento concomitante no acesso a fontes externas de financiamento e na liquidez dos ativos; e iv) a ausência de constrangimentos institucionais à expansão, caso do regime atual de política econômica que combina sistemas financeiros liberalizados (na dimensão externa e interna) e políticas monetárias concentradas unicamente no controle da inflação de curto prazo.

Outro elemento importante é a forma pela qual os ciclos financeiros domésticos relacionam-se, conformando um ciclo financeiro global. BIS (2014) e Borio (2012) concentramse em dois pontos: i) a reação imediata dos países avançados (principalmente, EUA) à Crise Financeira Global, bem como os limites das ações empreendidas; e ii) o impacto de tais medidas sobre os ciclos financeiros domésticos ao redor do mundo e a possibilidade de novos problemas. Nesse sentido, tais trabalhos reconhecem a centralidade das decisões estadunidenses na conformação do ciclo global e no condicionamento dos ciclos ao redor do mundo, todavia, as análises têm um foco mais pragmático, priorizando a reflexão sobre a combinação mais adequada de políticas para países em estágios diversos do ciclo financeiro doméstico - tópico de interesse da próxima seção. Já Rey (2013) sublinha a existência de um ciclo global, que hierarquiza e conecta os nacionais, bem como que a política monetária estadunidense cumpre um papel protagonista na determinação dos ciclos globais, influenciando o volume e a direção dos fluxos brutos de capital.

Do trabalho da autora francesa é possível depreender duas reflexões importantes. A primeira delas, diretamente exposta no trabalho, é que as condições monetárias estadunidenses são transmitidas através dos fluxos globais de capitais, condicionando um ciclo financeiro global que, obviamente, não é alinhado com condições macroeconômicas específicas dos países. Devido a isso, é possível afirmar que há um dilema (e não, um trilema) na macroeconomia aberta, não sendo possível a combinação de livre mobilidade de capitais e autonomia da política monetária. A segunda diz respeito ao nexo entre as conclusões de Rey (2013) e os argumentos de Cohen (2013) acerca do poder no sistema financeiro e monetário internacional.

Nesse sentido, o tratamento do ciclo financeiro global pela autora evidencia as duas dimensões do poder do dólar na hierarquia de moedas: i) autonomia, dado que pode reduzir ou postergar os custos do ajuste por meio de decisões referente à taxa de juros, as quais afetam a taxa de câmbio e, portanto, a competitividade das exportações e o montante da dívida externa (denominada na moeda doméstica); e ii) influência, pois a política monetária estadunidense dita o ritmo do ciclo financeiro global e dos fluxos de capitais, limitando os graus de liberdade da política econômica dos países emergentes e em desenvolvimento, as quais, na ausência de políticas defensivas que mitiguem a pressão externa, não têm como evitar a ascensão do ciclo financeiro doméstico. Isso ocorre porque, de um lado, a manutenção de uma taxa mais elevada de juros voltada para o desaquecimento da expansão doméstica da oferta de crédito leva à valorização cambial e ao influxo excessivo de capitais (repondo o aquecimento do crédito via financiamento externo), enquanto, por outro lado, a redução da taxa de juros, com o objetivo de evitar tais problemas, sanciona a ampliação do crédito interno e corrobora para a perda de autonomia da política monetária.

Tais estudos a respeito do ciclo financeiro global colocam um tema para discussão no que tange aos limites do RMI, principalmente, no caso de economias emergentes e sem moeda conversível como a brasileira. Assim, em períodos de ascensão cíclica, o influxo de capitais para países emergentes e em desenvolvimento favorece a sobrevalorização cambial, 
facilitando o controle da inflação e o cumprimento das metas. Todavia, em períodos de reversão, a brusca desvalorização cambial tende a gerar pressões inflacionárias a despeito de qualquer política monetária contracionista.

Dessa maneira, a literatura sobre ciclo financeiro global lança luz sobre duas fragilidades do RMI. Em primeiro, lugar, é possível que sua efetividade esteja relacionada a fatores externos à economia em questão. Adicionalmente, o foco no controle à inflação como principal objetivo da política econômica oculta demais problemas como a sobrevalorização cambial, o desequilíbrio na conta corrente e o influxo excessivo de capitais de curto prazo, os quais aprofundam a fragilidade financeira mesmo um contexto de inflação baixa.

\section{Regime de Metas de Inflação: uma revisão da literatura empírica}

Desde a implantação do Regime de Metas de Inflação (RMI) no Brasil, em 1999, a sua eficácia vem sendo amplamente debatido no meio acadêmico. Na presente seção, são apresentados trabalhos empíricos acerca do RMI brasileiro. Para fins didáticos, tal esforço de revisão foi organizado conforme a temática.

Em termos de credibilidade, Sicsú (2002) foi o primeiro a analisar empiricamente o RMI brasileiro. Neste trabalho, o autor pretende demonstrar as relações entre as expectativas inflacionárias e a teoria da reputação-credibilidade. Primeiramente o autor elabora um índice de credibilidade que mostra "quanto o mercado acredita que a meta pode ser alcançada" (SICSÚ, 2002, p. 706). O índice mostra que nos anos de 2000 e parte de 2001, grande parte do mercado acreditava que a meta de inflação estipulada pelo Conselho Monetário Nacional (CMN) seria alcançada. Contudo, com as crises em meados de 2001 (internamente, tivemos problemas de racionamento de energia, e externamente, o ataque terrorista aos Estados Unidos em setembro de 2001) a confiança do mercado se deteriora, fazendo com que as expectativas inflacionárias aumentassem, mostrando um piora consistente do índice calculado pelo autor. Ademais, o autor calculou o grau de dispersão das expectativas de inflação, que "pode ser considerado um indicador de homogeneidade/heterogeneidade das expectativas de inflação do mercado" (SICSÚ, 2002, p. 709) por meio de um coeficiente de variação amostral de Pearson. Claramente, o autor mostra que as expectativas de inflação se tornam mais heterogêneas entre os anos de 2000 e 2001, que reforça a ideia de insegurança por parte do mercado em acreditar na eficácia da política monetária por parte do Banco Central do Brasil (BCB). O autor conclui dizendo que se o BCB cumpre com sucesso as metas, as expectativas de inflação são influencias no início do ano seguinte e que se há um acúmulo de reputação e a meta não se torna crível ao longo do ano, as expetativas de inflação se tornam mais heterogêneas.

Na mesma linha, Mendonça (2004) tenta empiricamente mensurar a credibilidade do RMI brasileiro por meio de dois índices e analisar os resultados obtidos. Diferentemente do trabalho anterior, o autor se utiliza do índice elaborado por Cecchetti e Krause (2002) e proposto por Svensson (2000) em que a credibilidade é medida pela diferença a meta e a inflação esperada. Como resultado, o autor mostra que nos três primeiros anos RMI, o índice de credibilidade do BCB foi elevado (acima de 70\% de confiança). Contudo, o autor critica Sicsú (2002) pelo formato do índice utilizado e o reconstrói de forma a deixar o índice entre 0 (sem nenhuma confiança no BCB) e 1 (confiança total no BCB). Os resultados mostram que a partir de março de 2001 há uma ruptura na estabilidade, fazendo com que a confiança se deteriorasse rapidamente, fazendo com que não houvesse confiança nenhuma no BCB a partir de meados de 2001, e em 2002, a confiança não chega a $50 \%$ e volta a ser zero a partir de abril deste ano. Mendonça (2004) conclui argumentando que a estratégia de elaboração e sustentação do RMI foi equivocada, em relação a não utilização de válvulas de escape e metas muito ambiciosas e de longo prazo logo nos primeiros anos, em que há uma fase natural de 
ajustes entre a nova política monetária e o comportamento inflacionário brasileiro. Dessa forma, o autor sugere que o problema central não residiria no regime monetário adotado e sim na forma como as metas foram definidas a época, em termos de magnitude e em relação ao horizonte temporal (Mendonça, 2004).

Agora em termos dos efeitos da política monetária sobre os preços livres e administrados, temos o estudo de Mendonça (2007). O objetivo do autor é verificar qual a reação da taxa de juros pelo $\mathrm{BCB}$ em relação a inflação tendo origem nos preços livres e nos administrados, uma vez que o os preços administrados têm um peso relevante na composição do índice de preços do IPCA ${ }^{\ddagger \ddagger}$. Mendonça (2007) estima uma função de reação do BCB tendo estes preços como foco e os resultados obtidos mostra que o comportamento das taxas de juros estimada está muito próxima daquela observada ao longo do período analisado (1999 a 2004). Contudo, segundo o autor, "a resposta dos juros aos preços administrado, além de não ser desprezível, apresenta significância estatística bastante elevada. Logo, os prelos administrados têm contribuído para dificultar possíveis reduções na taxa Selic ${ }^{\S \S ”}$ (Mendonça, 2007 , p. 440). Em seguida, o autor utiliza um modelo de Vetores Autorregressivos(VAR) para estimar dois modelos: i) o primeiro para verificar o impacto dos preços livres e administrados sobre a taxa Selic; e ii) o quão impactante é a política que segue o RMI baseado no IPCA para a sociedade. O resultado do primeiro modelo mostra que "a autoridade monetária usa de forma efetiva a taxa de juros para neutralizar pressões inflacionárias oriundas de choques sobre a taxa de câmbio" (Mendonça, 2007, p. 442). Já o segundo modelo, o autor verifica que a política monetária, baseado no RMI, em que o combate à inflação se dá por meio da elevação da taxa de juros, leva a uma rigidez na redução da própria taxa de juros e que leve a um aumento permanente no nível de desemprego.

Na mesma linha Carrara e Correa (2012) analisam empiricamente o IPCA sob o modelo do RMI. Os autores, por meio de um modelo VAR, buscar verificar a eficiência de se ter o IPCA como índice de referência dado suas características. Eles consideraram no modelo proposto, além do IPCA, o IGP-M, um núcleo de inflação, o IPCA para os preços administrado, taxas de câmbio e de juros, além do hiato do produto. Como resultados os autores encontraram evidencias de que aumentos nos preços administrados geram aumentos persistentes no IPCA cheio. Ademais, o IPCA responde pouco a aumentos da taxa de juros, mas em contrapartida o núcleo de inflação, quando se exclui preços voláteis, responde de maneira consistente a aumentos da taxa de juros. Assim, os autores entendem que para o RMI brasileiro funcionar de maneira mais coerente, reduzindo seus ônus, a adoção de um núcleo de inflação seria uma saída viável.

Minella et al (2003) trata da credibilidade e do repasse cambial sob o RMI brasileiro no período de 1999 a 2002. Os autores estimaram diversos modelos de forma a medir a função de reação do $B C B$ (utilizando as expectativas do $B C B$ e do mercado), assim como a estimação das expectativas inflacionárias e a estimação da curva de demanda agregada. Nos dois primeiros modelos, os autores encontram como resultado, que a taxa de juros é determinada principalmente pelas expectativas de inflação, seguida pela taxa de juros do período anterior e pela taxa de câmbio. Já o terceiro modelo, os autores verificaram que as expectativas de inflação dos agentes privados estão ancoradas na meta de inflação, seguido das expectativas de inflação passada do mercado e pela inflação acumulada nos últimos doze meses. Por fim, os autores encontraram para a demanda agregada estimada um componente cambial importante, mostrando assim, que há repasse cambial na economia brasileira e que esse repasse ocorre principalmente nos preços administrados, impactando indiretamente o IPCA.

\footnotetext{
\#‡ Índices de Preços ao Consumidor Amplo calculado mensalmente pelo Instituto Brasileiro de Geografia e Estatística.

$\S \S$ Taxa de juros básica da economia brasileira.
} 
Nesse sentido, os trabalhos de Belaisch (2003) e Nogueira Jr. (2006) encontraram resultados parecidos no tocante ao repasse cambial na economia brasileira.

Já o estudo de Squeff (2009) inova ao mostrar a questão do repasse cambial "reverso" no Brasil entre os anos de 1999 e 2007, dando uma especial ênfase ao papel a valorização da taxa de câmbio brasileira na redução da inflação. O autor se utiliza do modelo VAR para estimar o repasse cambial no Brasil, realizando recortes temporais arbitrários, em que se evidencia períodos de variação cambial, seja ele de valorização ou de desvalorização, tendo compreendido todo o período de análise (1999 a 2007) e dois subperíodos (1999 a 2003 e 2003 a 2007). Os resultados encontrados demonstram que o repasse cambial mesmo caindo após a adoção do RMI, este ainda se mostra bastante elevado no segundo subperíodo analisado (2003 a 2007). Isso quer dizer, a política monetária utilizada pelo RMI tem se mostrado neste período menos eficaz do que a utilização da valorização da taxa de câmbio para controle da inflação.

O trabalho de Ferreira e Jayme Jr. (2005) analisa o desempenho do RMI brasileiro num cenário de excessiva volatilidade cambial, com elevada dívida pública e os impactos desta política sobre o produto. Os autores utilizaram o modelo VAR e obtiveram resultados significativos, que podem ser elencados em:

“i) a taxa de juros se comporta como um importante instrumento de política monetária; ii) há presença de inércia inflacionária; iii) alterações na taxa de juros com o intuito de conter pressões inflacionárias podem provocar efeitos opostos ao objetivado; iv) a taxa de inflação mostra-se bastante sensível às oscilações na taxa de câmbio; v) a taxa de inflação responde, de forma errática e não significativa, às variações no resultado nominal do governo; vi) a resposta da taxa de inflação às inovações no nível de utilização da capacidade instalada não é significativa; vii) a resposta do nível de utilização da capacidade instalada aos choques na taxa de inflação não revelou ser significativa; e viii) a política monetária afeta negativamente o nível de utilização da capacidade instalada" (Ferreira e Jayme Jr., 2005, p.1).

Como conclusão, os autores afirmam que o RMI brasileiro ainda possui limitações no tocante a descoordenações entre as políticas fiscal e monetária, assim como a vulnerabilidade externa, que impacta diretamente a volatilidade da taxa de câmbio a choques externos.

Com o intuito de verificar o comportamento das diversas variáveis macroeconômicas, Mendonça (2005) tenta verificar quais os impactos do RMI brasileiro, com enfoque na taxa de desemprego. $O$ autor se utiliza de modelo VAR com a utilização das variáveis: Selic, inflação, produção industrial, credibilidade das metas de inflação, além da variável desemprego. Os resultados obtidos mostraram que houve um desenvolvimento da credibilidade após a adoção do RMI, e que a utilização de uma política monetária contracionista tende a aumentar o desemprego e deprimir a produção industrial.

Já o estudo de Dezordi et al (2009) analisou a eficácia da política monetária sob o RMI no Brasil. Para tanto, os autores utilizam um modelo VAR, baseado na proposta de Taylor (1993), em que a resposta da política monetária deve ser maior a processos inflacionários do ao comportamento de hiato do produto. Os autores analisaram o período entre 1999 e 2006 e utilizaram as variáveis Selic, IPCA e hiato do produto, este último, calculado por meio do filtro $\mathrm{HP}^{* * *}$. Como resultado, os autores encontraram evidências que o RMI brasileiro responde muito mais por processos inflacionários do que ao hiato do produto, mostrando que a autoridade monetária tem como foco central a inflação e não o crescimento econômico.

\footnotetext{
*** O filtro Hodrick e Prescott (1997), também conhecido como filtro HP, é um método em que se suaviza a série analisada, separando o componente cíclico da tendência.
} 
Já o trabalho de Mendonça, Dezordi e Curado (2009) busca determinar empiricamente a taxa de juros da economia brasileira, seguindo a mesma linha de Dezordi et al. (2009), em que a taxa de juros é determinada por uma regra de Taylor. A inovação reside no fato de que os autores utilizaram, além das variáveis Selic, IPCA e hiato do produto, as variáveis taxa de juros real, que é a taxa de juros nominal (Selic) deflacionada pelo IPCA e o Risco-país, que é o diferencial da taxa de juros doméstica e a taxa de juros dos títulos públicos norte-americanos. O modelo utilizado foi o mesmo do trabalho anterior, o modelo de series temporais VAR e os resultados apontaram para uma dificuldade por parte do BCB em dosar a taxa de juros, de modo a alcançar a meta de inflação, gerando até mesmo efeitos inversos ao esperado. Outro resultado interessante e corrobora o estudo de Dezordi et al (2009) é a pouca importância dada pelo $\mathrm{BCB}$ ao hiato do produto. $\mathrm{A}$ autoridade monetária não trabalha com a política monetária voltada ao hiato do produto e sim, exclusivamente aos desvios das metas de inflação. Contudo, o resultado mais contundente é a resposta das taxas de juros a mudanças do risco-pais. A análise empírica evidenciou "fortes indícios de que a taxa de juros básica da economia brasileira tem sido utilizada com o principal objetivo de alcançar o equilíbrio do balanço de pagamentos" (Mendonça, Dezordi e Curado, 2009, p. 184).

Já o trabalho de Araújo e Modenesi (2011) visa analisar como ocorre a formação dos preços na economia brasileira entre os anos de 1999 e 2010 sob RMI. Os autores utilizam o modelo SVAR, que é um modelo VAR com um componente estrutural, que permite um maior controle na interação entre as variáveis. Segundo os autores, em linhas gerais, a formação de preços se deve a três componentes, a saber: i) demanda agregada; ii) oferta agregada; e iii) taxa de câmbio. Assim, as variáveis utilizadas foram o IPCA, Produção Industrial (como proxy da demanda agregada), um índice de preços das commodities (como proxy de oferta, e taxa de cambio. Como resultado, os autores encontraram evidencias de que o câmbio é mais intenso e duradouro em relação as demais variáveis para influenciar na inflação. Quando se decompõe o IPCA em preços livres e administrados, percebe-se que o câmbio impacta ambos os preços, mas pouco impacta no nível de atividade. Assim, os autores concluem que "a taxa de câmbio é, isoladamente, o componente mais relevante na determinação do IPCA, seguida pelo nível de atividade econômica e, finalmente, pelas condições de oferta" (ARAÚJO, MODENESI; 2011, p. 17).

O trabalho de Modenesi e Araújo (2013) segue a mesma linha ao evidenciar os impactos que a política monetária (taxa de juros) tem no nível de preços, na atividade econômica, no endividamento público e na taxa de cambio. Como resultados contundentes, os autores encontraram evidencias de que o câmbio é uma variável importante para determinação do nível de preços, assim como elevações da taxa de juros demoram a surtir efeito sobre o nível de preços e deprimem rapidamente a atividade econômica. Ademais, os autores concluem afirmando que os custos de se manter a inflação dentro da meta utilizando a taxa de juros são elevados, e que o câmbio é uma variável determinante para controlar inflação.

Por último, o trabalho de Fonseca, Oreiro e Araújo (2018), como o trabalho de Modenesi e Araújo (2013), visa analisar os impactos da política monetária sobre algumas variáveis macroeconômicas, com enfoque no comportamento não linear das variáveis. Os autores utilizaram o modelo de séries temporais MS-VAR, em que se agrega ao modelo VAR, correntes markovianas, com o intuito de se obter regimes definidos, de política monetária. Como resultado relevantes, os autores obtiveram dois regimes bem definidos tendo o primeiro regime entre 2000 e 2007 e o segundo, entre 2007 e 2013. Os efeitos de uma política monetária contracionista ficaram mais evidentes no segundo regime e teve efeitos persistentes sobre a dívida pública e a taxa de câmbio. 
Dada essa análise acerca dos trabalhos empíricos envolvendo o RMI brasileiro, percebe-se dois elementos importantes: o primeiro deles diz respeito a evolução na análise do RMI ao longo dos últimos 17 anos. Essa evolução se fez necessária como forma de avaliação da eficácia da política monetária, identificando possíveis pontos de estrangulamento. 0 segundo elemento diz respeito a não verificação e inclusão em nenhum desses trabalhos do componente grau de integração financeira e seus impactos para a política monetária brasileira sob o RMI. Dessa forma, a próxima seção será o de analisar como a integração financeira interfere na condução da política monetária.

\section{Os limites do Regime de Metas de Inflação: evidências empíricas a partir do modelo VEC}

Na presente seção, realiza-se o objetivo principal do presente artigo ao se estimar um modelo de vetores autorregressivos com correção de erros vetorial (VEC), o qual permite avaliar a interação entre variáveis que apresentam relação de cointegração, sem a necessidade de definições a priori acerca da ordem de causalidade e determinação das variáveis, considerando todas as variáveis como endógenas. Tal exercício empírico baseou-se no modelo estimado por Modenesi e Araújo (2013), composto pelas cinco variáveis expostas na seção anterior. Além dessas variáveis, destaca-se, como contribuição potencialmente original, a inclusão da dimensão financeira interna e externa. A dimensão interna está representada pelo grau de integração financeira da economia brasileira (IIF), mensurado por meio da razão entre a soma bruta dos fluxos de capitais (entrada e saída) e o produto nominal. Segue-se, portanto, a linha de Kraay (1998), considerando os mesmos fluxos de Cunha e Laan (2013). A dimensão externa, por sua vez, passa pela consideração do ciclo financeiro global ${ }^{\dagger+\dagger}$. Assim, estima-se um modelo composto por sete variáveis, as quais sofreram tratamento por meio de ajuste sazonal e transformação monotônica em logaritmo natural. Veja a Tabela 1 abaixo:

Tabela 1. Especificação dos dados

\begin{tabular}{|c|c|c|}
\hline Série & Nome & Descrição \\
\hline Ciclo Financeiro Global & VIX & $\begin{array}{l}\text { Índice de Volatilidade, calculado pelo CBOE - média } \\
\text { mensal. }\end{array}$ \\
\hline $\begin{array}{l}\text { Índice de Integração } \\
\text { Financeira }\end{array}$ & IIF & Índice explicado no começo da seção. \\
\hline Nível de Atividade & IND & $\begin{array}{l}\text { Produção industrial - indústria geral - quantum - } \\
\text { índice dessazonalizado (média } 2002=100 \text { ), divulgado } \\
\text { na PIM/IBGE. }\end{array}$ \\
\hline Taxa de Câmbio & CAMBIO & $\begin{array}{l}\text { Série BC } 3697 \text { - Taxa de Câmbio livre - Média mensal, } \\
\text { divulgada pelo Depec. }\end{array}$ \\
\hline $\begin{array}{l}\text { Dívida Líquida do Setor } \\
\text { Público }\end{array}$ & DIV & $\begin{array}{l}\text { Percentual da dívida líquida do setor público em } \\
\text { proporção do PIB mensal, divulgada pelo IBGE }\end{array}$ \\
\hline Taxa de Juros & SELIC & $\begin{array}{l}\text { Série BC } 4189 \text { - Taxa de juros - Selic acumulada no } \\
\text { mês anualizada - \% a.a., divulgada pelo Demab. }\end{array}$ \\
\hline Índice de Preços & IPCA & $\begin{array}{l}\text { Índice Nacional de Preços ao Consumidor Ampla } \\
\text { (IPCA) - série em base } 100 \text { em janeiro de } 1995\end{array}$ \\
\hline
\end{tabular}

Fonte: Instituto de Pesquisa Econômica Aplicada (IPEA); Banco Central do Brasil (BCB).

\footnotetext{
${ }^{++t}$ Segundo Nier, Sedik e Mondino (2014), a literatura empírica acerca do ciclo financeiro global utiliza o VIX como medida da aversão ao risco e da incerteza no mercado financeiro global, já que o índice aponta a expectativa de volatilidade no mercado de ações ao longo dos próximos trinta dias. Em momentos de ascensão do ciclo financeiro global, verifica-se um baixo nível de volatilidade; já nos momentos de declínio, observa-se um nível mais elevado de volatilidade.
} 
Como exposto anteriormente, a implementação formal do RMI no Brasil ocorreu a partir de 2000, constituindo-se assim uma mudança na condução da política monetária. Nesse sentido, parte-se de dados referentes ao período que vai de janeiro de 2000 até dezembro de $2014^{\ddagger \ddagger \neq}$. Segundo Woodridge (2002), uma estimação apresenta um grau de confiança suficiente quando cumpre duas condições: (i) possui mais de 60 observações; (ii) estima um número de parâmetros inferior ao total de observações. No exercício a seguir, ambas as condições são atendidas, pois foram estimados 156 parâmetros a partir de 180 observações.

Dada a existência de quebras estruturais em todas as variáveis do modelo, procedeuse o tratamento de todas as séries a partir do modelo estrutural de Harvey (1989), o qual permite a estimação do nível da variável em questão, separando a evolução deste de eventuais quebras e outliers. Dessa maneira, ao invés de se impor uma dummy de intervenção nos meses em que se sucederam alterações nos níveis das variáveis endógenas, opta-se por tratar cada série separadamente, a partir do software STAMP, para, após isso, passar à modelagem VEC propriamente dita, por meio do software EViews.

Após isso, passa-se ao primeiro passo da identificação do modelo VEC consiste na verificação do grau de integração das séries envolvidas. Assim, foram realizados os testes ADF (Dickey-Fuller aumentado), PP (Phillips-Perron) e KPSS (Kwiatkowski-Phillips-Schmidt-Shin). A tabela 2 aponta o caráter não estacionário de todas as séries em nível, a 95\% de confiança, em ao menos um dos testes realizados, e, consequentemente, a viabilidade da estratégia de estimação assentada na modelagem VEC.

O próximo passo consiste na determinação da estrutura adequada de defasagens, ou seja, o número de lags necessários para capturar as inter-relações dinâmicas no modelo VEC. Para isso, foram observados os critérios de informação de Akaike (AIC) e Schwarz (SBC), bem como o comportamento dos resíduos. Parte-se de um número mínimo de defasagens igual a 2 , uma vez que é a quantidade mínima para se atingir raízes complexas no sistema considerado de equações. A tabela 3 sumariza as estatísticas de AIC, SBC e os testes de autocorrelação residual (Multiplicador de Lagrange) e heteroscedasticidade (White).

\footnotetext{
¥¥¥ $\mathrm{O}$ passo inicial de um trabalho assentado na Econometria de Séries de Tempo é a delimitação do período temporal. Aqui, optou-se por uma amostra que vai de janeiro de 2000 a dezembro de 2014, constituindo um período de quinze anos. Reconhece-se que o ideal seria dispor de mais observações, não obstante se adota o Plano Real enquanto marco inicial, afinal, a utilização de dados anteriores poderia dificultar a modelagem, devido à volatilidade macroeconômica do período inflacionário. Quanto ao marco final, a instabilidade da economia brasileira nos últimos dois anos torna difícil a geração de resíduos bem-comportados na estimação do modelo VEC.
} 
Tabela 2. Testes de raiz unitária - séries ajustadas - valores de probabilidade

\begin{tabular}{|c|c|c|c|c|c|c|c|c|}
\hline \multicolumn{9}{|c|}{ Teste ADF de raiz unitária } \\
\hline Inclusão no teste & \multicolumn{8}{|c|}{ Em nível } \\
\hline Variáveis & & VIX & IIF & IPCA & DIV & IND & CAMBIO & SELIC \\
\hline Com constante & Probabilidade & 0.4379 & 0.234 & 0.4379 & 0.9571 & 0.4872 & 0.8045 & 0.1788 \\
\hline $\begin{array}{l}\text { Com constante e } \\
\text { tendência }\end{array}$ & Probabilidade & 0.1547 & 0.456 & 0.3432 & 0.1958 & 0.7279 & 0.9265 & 0.0479 \\
\hline $\begin{array}{l}\text { Sem constante e } \\
\text { tendência }\end{array}$ & Probabilidade & 0.3151 & 0.754 & 1.0000 & 0.2343 & 0.9873 & 0.7814 & 0.3935 \\
\hline Inclusão no teste & \multicolumn{8}{|c|}{ Em primeira diferença } \\
\hline & & $\mathrm{d}(\mathrm{VIX})$ & $d(I I F)$ & $d(I P C A)$ & $d(D I V)$ & $d(I N D)$ & $\mathrm{d}(\mathrm{CAMBIO})$ & $\mathrm{d}(\mathrm{SELIC})$ \\
\hline Com constante & Probabilidade & 0.0000 & 0.000 & 0.0000 & 0.0000 & 0.0000 & 0.0000 & 0.0003 \\
\hline $\begin{array}{l}\text { Com constante e } \\
\text { tendência }\end{array}$ & Probabilidade & 0.0000 & 0.000 & 0.0001 & 0.0000 & 0.0000 & 0.0000 & 0.0022 \\
\hline $\begin{array}{c}\text { Sem constante e } \\
\text { tendência }\end{array}$ & Probabilidade & 0.0000 & 0.000 & 0.0198 & 0.0000 & 0.0000 & 0.0000 & 0.0000 \\
\hline \multicolumn{9}{|c|}{ Teste PP de raiz unitária } \\
\hline Inclusão no teste & \multicolumn{8}{|c|}{ Em nível } \\
\hline & & VIX & IIF & IPCA & DIV & IND & CAMBIO & SELIC \\
\hline Com constante & Probabilidade & 0.5162 & 0.349 & 0.4020 & 0.9579 & 0.4860 & 0.7199 & 0.4844 \\
\hline $\begin{array}{l}\text { Com constante e } \\
\text { tendência }\end{array}$ & Probabilidade & 0.1393 & 0.573 & 0.6713 & 0.1625 & 0.7040 & 0.8517 & 0.3152 \\
\hline $\begin{array}{c}\text { Sem constante e } \\
\text { tendência }\end{array}$ & Probabilidade & 0.2713 & 0.747 & 1.0000 & 0.2626 & 0.9877 & 0.7546 & 0.4231 \\
\hline Inclusão no teste & \multicolumn{8}{|c|}{ Em primeira diferença } \\
\hline & & $\mathrm{d}(\mathrm{VIX})$ & $d(I I F)$ & $d(I P C A)$ & $d(D I V)$ & $d(I N D)$ & $\mathrm{d}(\mathrm{CAMBIO})$ & $\mathrm{d}(\mathrm{SELIC})$ \\
\hline Com constante & Probabilidade & 0.0000 & 0.000 & 0.0000 & 0.0000 & 0.0000 & 0.0000 & 0.0210 \\
\hline $\begin{array}{l}\text { Com constante e } \\
\text { tendência }\end{array}$ & Probabilidade & 0.0000 & 0.000 & 0.0001 & 0.0000 & 0.0000 & 0.0000 & 0.0866 \\
\hline $\begin{array}{c}\text { Sem constante e } \\
\text { tendência }\end{array}$ & Probabilidade & 0.0000 & 0.000 & 0.0381 & 0.0000 & 0.0000 & 0.0000 & 0.0014 \\
\hline \multicolumn{9}{|c|}{ Teste KPSS de raiz unitária } \\
\hline Inclusão no teste & \multicolumn{8}{|c|}{ Em nível } \\
\hline & & VIX & IIF & IPCA & DIV & IND & CAMBIO & SELIC \\
\hline Com constante & t-calculado & 1.1648 & 0.236 & 1.7074 & 1.4221 & 1.6601 & 0.9804 & 1.3859 \\
\hline $\begin{array}{l}\text { Com constante e } \\
\text { tendência }\end{array}$ & t-calculado & 0.1167 & 0.117 & 0.2978 & 0.2598 & 0.2455 & 0.2011 & 0.111 \\
\hline Inclusão no teste & \multicolumn{8}{|c|}{ Em primeira diferença } \\
\hline & & $d(V I X)$ & $d(I I F)$ & $d(I P C A)$ & $d(D I V)$ & $d(I N D)$ & $d(C A M B I O)$ & $\mathrm{d}($ SELIC) \\
\hline Com constante & t-calculado & 0.0565 & 0.076 & $0.3494 *$ & $0.4311^{*}$ & 0.1655 & 0.27 & 0.0609 \\
\hline $\begin{array}{l}\text { Com constante e } \\
\text { tendência }\end{array}$ & t-calculado & 0.051 & 0.065 & $0.1277^{*}$ & $0.1687^{* *}$ & 0.0493 & $0.2699 * * *$ & 0.0569 \\
\hline
\end{tabular}

Fonte: Elaboração própria. Nota: Valores-p baseado em MacKinnon (1996). 
Tabela 3. Critério de informação de Akaike e Schwarz, teste de autocorrelação residual Multiplicador de Lagrange e teste White de heteroscedasticidade

\begin{tabular}{c|c|c|c|c|c|c|c}
\hline Ordem & \multicolumn{2}{|c|}{2} & \multicolumn{2}{|c}{3} & \multicolumn{2}{c}{4} \\
\hline \multirow{6}{*}{} & AIC & SBC & AIC & SBC & AIC & SBC \\
\cline { 2 - 7 } & $-37,14$ & $-35,00$ & $-37,06$ & $-34,03$ & $-36,94$ & $-33,02$ \\
\hline \multicolumn{7}{|c}{ Teste de Autocorrelação Residual LM } \\
\hline Ordem & Est. & p-valor & Est. & $p$-valor & Est. & $p$-valor \\
\hline 1 & 73,39 & 0,0136 & 64,49 & 0,0680 & 64,77 & 0,0649 \\
2 & 70,41 & 0,0241 & 65,48 & 0,0577 & 65,61 & 0,0565 \\
3 & 55,13 & 0,2542 & 52,02 & 0,3571 & 54,10 & 0,2858 \\
4 & 56,38 & 0,2183 & 53,92 & 0,2918 & 54,08 & 0,2866 \\
5 & 65,96 & 0,0533 & 60,77 & 0,1207 & 54,86 & 0,2622 \\
6 & 35,51 & 0,9255 & 43,46 & 0,6966 & 41,33 & 0,7738 \\
7 & 47,80 & 0,5219 & 43,69 & 0,6877 & 47,86 & 0,5195 \\
8 & 60,39 & 0,1275 & 51,90 & 0,3615 & 53,91 & 0,2920 \\
9 & 45,87 & 0,6009 & 58,29 & 0,1707 & 55,81 & 0,2342 \\
10 & 31,09 & 0,9785 & 37,67 & 0,8807 & 39,80 & 0,8230 \\
11 & 44,05 & 0,6735 & 46,19 & 0,5876 & 45,46 & 0,6175 \\
12 & 51,01 & 0,3947 & 46,77 & 0,5641 & 55,43 & 0,2450 \\
\hline
\end{tabular}

Teste de Heterodecasticidade de White - p-valor

\begin{tabular}{c|c|c|c}
\hline Ordem & 2 & 3 & 4 \\
\hline & 0,0041 & 0,0815 & 0,0854 \\
\hline
\end{tabular}

Fonte: elaboração própria.

Em primeiro lugar, observa-se que, em qualquer das defasagens analisadas, não há problema de autocorrelação residual até a 12 a ordem, considerando um nível de significância de $5 \%$. No que tange aos critérios de informação, tanto o AIC quanto o SBC apontam a estrutura de estimação com 2 defasagens como a mais adequada. Não obstante, todas as formatações com número de defasagens inferior a 3 apresentam autocorrelação e heteroscedasticidade residual, partindo de um nível de significância de $5 \%$. Isso é corrigido a partir da estimação de um VEC (3), o qual supera o de ordem 4 segundo os critérios de AIC e $\mathrm{SBC}$, bem como apresenta resíduos que se aproximam de um ruído branco, considerando um grau de confiança de $95 \%$. Dito isso, realiza-se o teste de Johansen, conforme Johansen e Juselius (1990), com o objetivo de delimitar a existência e o número de equações cointegradas. 
Tabela 4 - Teste de cointegração de Johasen para um VEC (3)

\begin{tabular}{l|c|c|c|l}
\hline $\begin{array}{c}\text { No de eq. } \\
\text { Cointegradas }\end{array}$ & Estatística Traço & VC - 5\% & EstatísticaMáximo-Autovalor & VC - 5\% \\
\hline Nenhuma & 159,0542 & 125,6154 & 59,7432 & 46,2314 \\
Até 1 & 99,3111 & 95,7537 & 46,2838 & 40,0776 \\
Até 2 & 53,0273 & 69,8189 & 24,5787 & 33,8769 \\
Até 3 & 28,4486 & 47,8561 & 15,1255 & 27,5843 \\
Até 4 & 13,3231 & 29,7971 & 7,6107 & 21,1316 \\
\hline
\end{tabular}

Fonte: elaboração própria. Obs: Quando a estatística supera o valor crítico (VC), rejeita-se a hipótese nula de ausência de cointegração, considerando um nível de confiança de $95 \%$.

A tabela acima aponta a existência de cointegração pelos critérios de traço e de máximo-autovalor, partindo-se de um grau de confiança de 95\%. De acordo com Dickey, Jansen e Thornton (2007), se há relações de cointegração entre as variáveis, o sistema de equações torna-se mais estável, de modo que o sistema estimado é estacionário em um conjunto de possíveis direções, possibilitando a estimação do modelo VEC.

Dado que o modelo está especificado adequadamente, passa-se à avaliação das funções de resposta ao impulso. A análise organiza-se em torno de três aspectos: (i) os desdobramentos de uma elevação da taxa de juros sobre o nível de preços e a taxa de câmbio; (ii) a resposta do nível de preços frente à taxa de câmbio; e (iii) a relação entre o ciclo financeiro global e a evolução da taxa de câmbio da economia brasileira. Para fins de organização, apenas as respostas referentes a esses eixos foram plotadas no corpo do presente trabalho. Veja os gráficos das funções de resposta ao impulso na figura abaixo: 
Figura 1. Funções de resposta ao impulso estimadas a partir do modelo VEC (3) $)^{\S \S}$

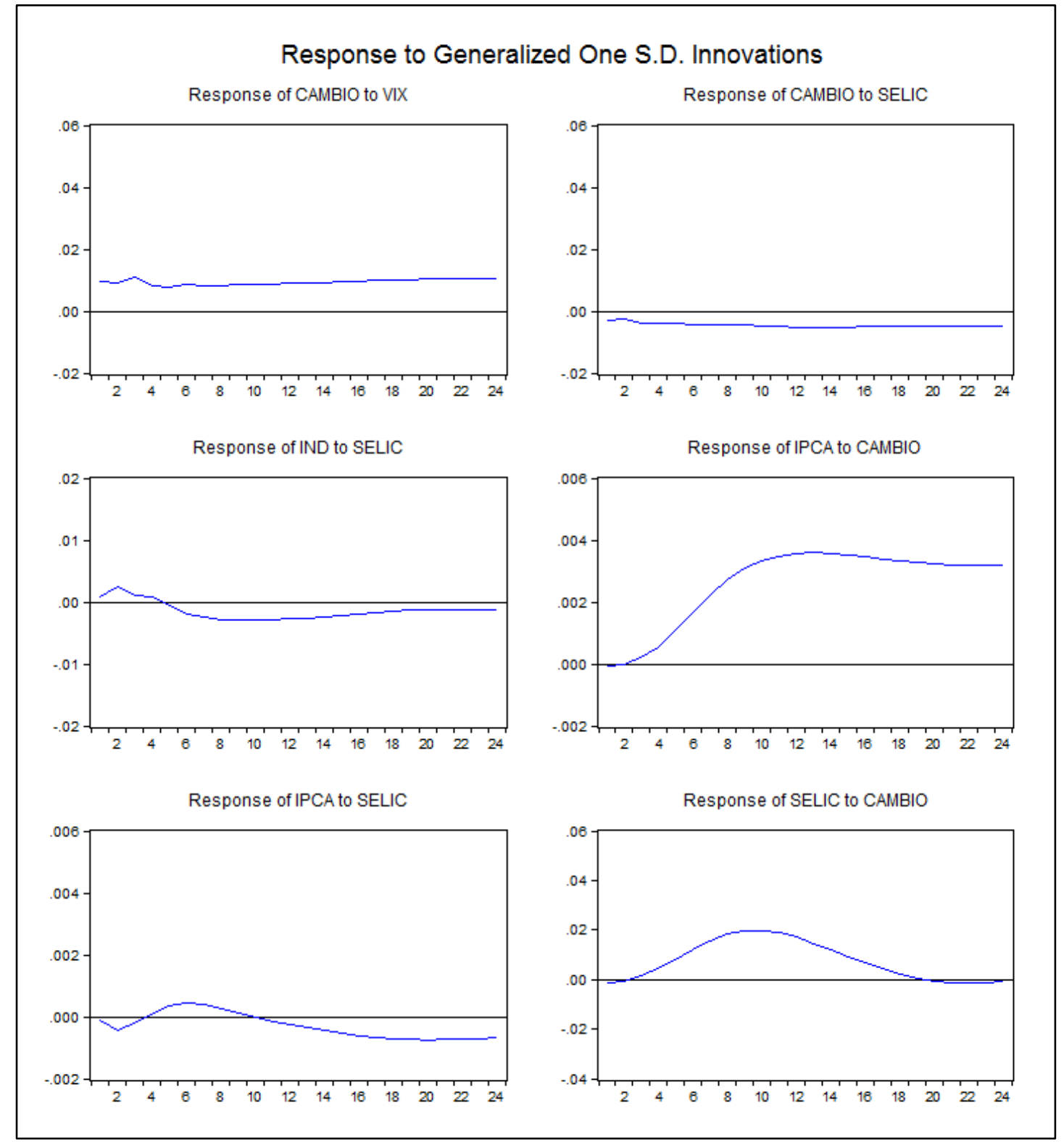

Fonte: elaboração própria.

Passando ao primeiro eixo, os resultados parecem reforçar os argumentos da literatura crítica ao Regime de Metas de Inflação. Dessa maneira, observa-se que um choque positivo na taxa de juros está associado, em um primeiro momento, um aumento do nível de preços,

\footnotetext{
${ }^{\S \S}$ Tsay (2005) sublinha que, tal como os modelos univariados, um VAR pode ser escrito como um vetor de médias móveis, isto é, como uma função linear dos choques passados $\left(x_{t}=\mu+\sum_{i=0}^{\infty} \emptyset_{i} \varepsilon_{t-i}\right)$. Dessa maneira, os coeficientes $\emptyset_{\mathrm{i}}$ transmitem o efeito de choques nas diversas séries do modelo à própria trajetória destas. Uma função de resposta ao impulso é, portanto, fruto do acúmulo dos efeitos de um choque em determinada série sobre a própria série ou outra que componha o modelo em questão. Segundo Enders (2010), a decomposição de Choleski apresenta o problema de que a alteração da ordem das equações pode alterar dramaticamente as respostas aos impulsos. Frente a isso, Pesaran e Shin (1998) propuseram uma função de resposta a impulsos generalizados, as quais não dependem da ordem das variáveis em questão e consistem na aplicação de um fator de Choleski específico para cada variável no sistema.
} 
dando suporte à existência do fenômeno do price-puzzle. Sublinha-se também que um choque positivo na taxa de juros associa-se a uma reação negativado nível de atividade.

Outro aspecto a ser destacado guarda relação com o segundo eixo de análise. Assim, um choque positivo na taxa de juros relaciona-se a um processo de sobrevalorização cambial, ao ter um impacto negativo sobre a taxa de câmbio. Dado que a função de resposta ao impulso aponta uma relação direta entre nível de preços e taxa de câmbio, um quadro de sobrevalorização cambial pode contribuir para o controle da inflação. Nesse sentido, há o risco de que o RMI seja mais efetivo por meio de um canal indireto, a sobrevalorização cambial, que engendra consequências negativas tais como o aprofundamento da desindustrialização e da especialização regressiva da economia brasileira.

No terceiro eixo, observa-se a resposta da taxa de câmbio a um choque no ciclo financeiro global. No modelo estimado, tal ciclo é representado por um indicador de volatilidade das expectativas e aversão ao risco (VIX), de modo que em momentos de ascensão do ciclo financeiro global, verifica-se um baixo nível de volatilidade; já nos momentos de declínio, observa-se um nível mais elevado de volatilidade. Como a função de resposta ao impulso mostra uma relação direta entre o VIX e a taxa de câmbio, então, abre-se espaço para a discussão do nexo entre a sobrevalorização cambial e a ascensão do ciclo financeiro global, associação que foi observada no período que precedeu a crise de 2007-2008 e no que se seguiu à política monetária não-convencional por parte do banco central estadunidense.

Tendo em vista os resultados obtidos, sublinha-se que o principal objetivo do presente artigo consiste em apontar uma agenda de pesquisa, capaz de adensar o mecanismo causal acionado pela abordagem pós-keynesiana no que tange à avaliação dos custos e benefícios do Regime de Metas de Inflação. Nesse sentido, os resultados mostraram-se convergentes aos exercícios de Fonseca, Oreiro e Araújo (2017), como o trabalho de Modenesi e Araújo (2013), que associam a efetividade do principal instrumento de política monetária do RMI, a manipulação da taxa de juros, ao canal de transmissão cambial, com efeitos problemáticos sobre o desempenho da economia brasileira. Por outro lado, a associação entre a sobrevalorização cambial e a ascensão do ciclo financeiro global coloca o risco de que o cumprimento das metas de inflação não seja um desdobramento apenas da política monetária, mas sim da evolução do ciclo financeiro global, o que explicaria a maior dificuldade no cumprimento das metas de inflação após as ameaças de reversão da política monetária expansionista e não-convencional estadunidense, a despeito da manutenção das altas taxas de juros no Brasil.

Por fim, reconhece-se as limitações empíricas do presente exercício, dado que o comportamento das funções de resposta ao impulso não implica uma relação de causalidade. Por outro lado, a combinação de resultados convergentes à literatura acerca do tema com aspectos adicionais, relacionados ao movimento do ciclo financeiro global, são suficientes para chamar atenção para relevância da dimensão financeira externa no desempenho do Regime de Metas de Inflação no Brasil.

\section{Considerações finais}

O presente artigo avaliou a relação entre a taxa básica de juros e o nível geral de preços com foco no Brasil durante o Regime de Metas de Inflação. Do ponto de vista teórico, foi apresentada a crítica pós-keynesiana ao Novo Consenso Macroeconômico e, consequentemente, ao Regime de Metas de Inflação. Além disso, incorporou-se a interação entre tal problema de pesquisa e a dimensão financeira, considerando a literatura recente acerca do impacto do ciclo financeiro global sobre economias emergentes e em desenvolvimento. Após uma breve revisão da literatura empírica, estimou-se um modelo de vetores autorregressivos com correção de erros (VEC) a partir de uma amostra mensal que vai 
de janeiro de 2000 a dezembro de 2014. Adicionalmente, sendo esta uma contribuição potencialmente original em linha com a discussão teórica prévia, foram incluídas variáveis como ciclo financeiro global e grau de integração financeira externa.

Esse exercício empírico gerou resultados em linha com a crítica pós-keynesiana ao Regime de Metas de Inflação. Nesse sentido, em primeiro lugar, observou-se que o aumento da taxa básica de juros, principal instrumento do regime, pode gerar uma resposta mista por parte inflação. Assim, quando avaliada isoladamente, uma política monetária contracionista pode ter um efeito inflacionário devido ao fenômeno do price-puzzle. Além disso, a efetividade do controle inflacionário pode ser decorrência da sobrevalorização cambial, promovida tanto pela elevação da taxa de juros quanto pelo movimento do ciclo financeiro global. Dessa maneira, há o risco de que aqueda da taxa de câmbio da brasileira em períodos de ascensão do ciclo facilite o cumprimento da meta durante tais períodos. Por fim, tais resultados não pretendem esgotar a discussão sobre o tema, mas sim colocar uma agenda de pesquisa a ser aprofundada em trabalhos futuros.

\section{Referências}

Angeriz, A. e Arestis, P. (2007a) "Assessing the performance of 'inflation targeting lite' countries", The World Economy, 30(11), p. 1621-1645.

Angeriz, A. e Arestis, P. (2007b) "Monetary policy in the UK." Cambridge Journal of Economics, 31(6), p. 863-884.

Angeriz, A. e Arestis, P. (2008) "Assessing inflation targeting through intervention analysis." Oxford Economic Papers, 60(2), p.293-317.

Angeriz, A. e Arestis, P. (2009) "The consensus view on interest rates and fiscal policy: reality or innocent fraud?"Journal of Post Keynesian Economics, 31(4), p. 567-586.

Araujo, A. (2013) "Avaliação crítica do regime de metas de inflação a partir de uma ótica póskeynesiana."Análise Econômica, 31(60), p. 149-173.

Araujo, E. e Modenesi, A. (2011) "A Importância Do Setor Externo Na Evolução Do IPCA: Uma Análise Com Base Em Um Modelo SVAR.", 38o Encontro Nacional de Economia da ANPEC, Salvador. Disponível em <https://goo.gl/MVbr7Q>. Acessado em 15/03/2017.

Arestis, P. (2009) "The new consensus in macroeconomics: a critical appraisal." In: G. Fontana and M. Setterfield (eds.) Macroeconomic theory and macroeconomic pedagogy, London: Palgrave Macmillan, 1ed., p. 100-117.

Arestis, P., Baddeley, M. e Sawyer, M. (2007) "The relationship between capital stock, unemployment and wages in nine EMU countries."Bulletin of Economic Research, 59(2), p.125-148.

Arestis, P., Ferrari Filho, F. e Paula, L. F. (2011) "Inflation targeting in Brazil. International." Review of Applied Economics, 25(2), p.127-148.

Arestis, P., Paula, L. F., Ferrari Filho, F. (2007) "Inflation targeting in emerging countries: the case of Brazil." In: P. Arestis e A. Saad-Filho (eds) Political Economy of Brazil, London: Palgrave Macmillan, 1ed., p. 116-140.

Arestis, P. e Sawyer, M. (2002a) "The Bank of England macroeconomic model: its nature and implications."Journal of Post Keynesian Economics, 24(4), 529-545. 
Arestis, P. e Sawyer, M. (2002b) "Does the stock of money have any causal significance?"Annandale-on-Hudson, New York: The Levy Economics Institute. Working Paper Series, n. 363.

Arestis, P. e Sawyer, M. (2004) "On fiscal policy and budget deficits. Intervention."Journal of Economics, 1(2), p. 61-74.

Arestis, P. e Sawyer, M. (2006) "The nature and role of monetary policy when money is endogenous." Cambridge Journal of Economics, 30(6), p. 847-860.

Arestis, P. e Sawyer, M. (2008a) "A critical reconsideration of the foundations of monetary policy in the new consensus macroeconomics framework." Cambridge Journal of Economics, 32(5), p. 761-779.

Arestis, P. e Sawyer, M. (2008b) "New consensus macroeconomics and inflation targeting: Keynesian critique." Economia e Sociedade, 17 (SPE), p. 629-653.

Banco Central do Brasil (2003) Series Temporais. Disponível em <https://goo.gl/rcUjyq>. Acessado em 01/03/2017.

Bank for International Settlements (2014) 84th Annual Report. Basle: BIS. Disponível em <https://goo.gl/TY64G5>. Acessado em 01/05/2015.

Belaisch, A. (2003) "Exchange rate pass-through in Brazil". International Monetary Fund (IMF) Working Papers no 141.

Bernanke, B. (2003) "Friedman's monetary framework: some lessons", Proceedings, issue Oct, p. 207-217.

Borio, C. (2012) "The financial cycle and macroeconomics: What have we learnt?" BIS Working Papers, n. 395.

Borio, C. (2014) "The international monetary and financial system: its Achilles heel and what to do about it."BIS Working Papers, n. 456.

Borio, C., James, H. e Shin; H. (2014) "The international monetary and financial system: a capital account historical perspective", BIS Working Papers, n. 457.

Bresser-Pereira, L. C. (2006) "O novo desenvolvimentismo e a ortodoxia convencional."São Paulo em perspectiva, 20(3), p. 5-24.

Bresser-Pereira, L. C. (2012) "A taxa de câmbio no centro da teoria do desenvolvimento." Estudos avançados, 26(75), p. 7-28.

Carrara, A. e Correa, A. (2012) "O regime de metas de inflação no Brasil: uma análise empírica do IPCA."Revista de Economia Contemporânea, 16(3), p. 441-462.

Cecchetti, S. e Krause, S. (2002) "Central Bank Structure, Policy Efficiency, and Macroeconomic Performance: Exploring Empirical Relationships". Review, Federal Reserve Bank of St. Louis, p. 47-60.

Cohen, B. (2013) "Currency and State Power." In: M. Finnemore e J. Goldstein (eds.) Back to Basics: State Power in a Contemporary World, New York: Oxford University Press.

Colander, D. (2000) "The death of neoclassical economics."Journal of History of Economic Thought, 22(2), p. 127-143.

Cunha, A. e Laan, C. (2013) "Uma nova ordem financeira internacional? Avaliando alternativas para o Brasil."BNDES/PDE (2012). Disponível em <https://goo.gl/yxGYDW>. Acessado em 01/03/2017. 
Davidson, P. (2003) Financial markets, money, and the real world. Cheltenham: Edward Elgar Publishing.

Davidson, P. (1991) Inflation, Open Economies and Resources: The Collected Writings of Paul Davidson (Vol. 2), London: Palgrave Macmillan.

Dezordi, L., D’Agostini, L., Bittencourt, M. e Curado, M. (2009) “Regime de Metas de Inflação para a Condução da Política Monetária Brasileira: uma aplicação do modelo VAR." In: J. L. Oreiro, L. F. de Paula e R. Sobreira (eds.) Política Monetária, Bancos Centrais e Metas de Inflação: teoria e experiência brasileira, Rio de Janeiro: Editora FGV, 1ạ ed., p. 121147.

Dickey, D., Jansen, D. e Thornton, D. (2007) "A primer on cointegration with an application to money and income." In: B. RAO (ed.), Cointegration for the applied economist. New York City: Palgrave Macmillan.2ㄹed., p. 9-45.

Eichenbaum, M. (1992) Comment on "Interpreting the Macroeconomic Time Series Facts: The Effects of Monetary Policy" European Economic Review, 36, p. 1001-1011.

Enders, W. (2010) Applied Econometric Time Series. Nova York: John Wiley \& Sons.

Ferrari Filho, F. (1996) "Keynesianos, monetaristas, novos-clássicos e novos-keynesianos: uma crítica pós-keynesiana."Ensaios FEE, 17(2), p. 78-101.

Ferreira, A. e Jayme Jr, F. (2005) "Metas de inflação e vulnerabilidade externa no Brasil.",33o Encontro Nacional de Economia da ANPEC, Natal. Disponível em $<$ https://goo.gl/XSHfwa>. Acessado em 01/03/2017.

Fonseca, M., Oreiro, J. e Araujo, E. (2018) "The Nonlinearity of Brazilian Monetary Policy in the Inflation-Targeting Period: an analysis based on an MS-VAR model." Análise Econômica. No prelo.

Fontana, G. (2006) "The New Consensus' View of Monetary Policy: A New Wicksellian Connection?"The Levy Economics Institute Working Paper, n. 476.

Ghosh, A., Qureshi, M. e Sugawara, N. (2014) "Regulating Capital Flows at Both Ends: Does it Work?" International Monetary Fund (IMF) Working Paper n. 14/188.

Hallett, A. (2000) "Aggregate Phillips curves are not always vertical: heterogeneity and mismatch in multiregion or multisector economies."Macroeconomic Dynamics, 4(4), p. 534-546.

Harvey, A. (1989) Forecasting Structural Time Series Models and the Kalman Filter. Cambridge: Cambridge University Press.

Hein, E. e Schoder, C. (2011) "Interest rates, distribution and capital accumulation-A PostKaleckian perspective on the US and Germany."International Review of Applied Economics, 25(6), p. 693-723.

Hein, E. e Truger, A. (2008) "Fiscal policy in the macroeconomic policy mix: A critique of the New Consensus Model and a comparison of macroeconomic policies in France, Germany, the UK and Sweden from a Post-Keynesian perspective", IMK working paper, n. $03 / 2008$.

Johansen, S. e Juselius, K. (1990) "Maximum likelihood estimation and inference on cointegration with applications to demand for money."Oxford Bulletin of Economics Statistics, 52(2), p. 169-210. 
Juselius, M. (2008) "Testing the New Keynesian Nodel on US and Euro Area Data." Economics: The Open-Access, Open-Assessment E-Journal, 2 (2008-24) p. 1-26.

Kaldor, N. (1988) "The role of effective demand in the short and long-run growth." In: A. Barrére (Org.) The foundations of keynesian analysis. London: Palgrave Macmillan Press, p. 153-160.

Keynes, J. M. (1973) A treatise on probability, The Collected Writings of John Maynard Keynes, v. 8, London: MacMillan.

Keynes, J. M. (1982) A teoria geral do juro, do emprego e da moeda. São Paulo: Atlas.

Kraay, A. (1998) "In Search of Macroeconomic Effects of Capital Account Liberalization."World BankWashington D.C. Working Paper, Disponivel em <https://goo.gl/x2sFcB>. Acessado em 29/01/2018.

Lavoie, M. (1993) "Mr Keynes and the Post Keynesians: Principles of Economics for a Monetary Production Economy." Journal of Economic Issues, 27(4), p. 1300-1303.

Ledesma, M. (2002) "Accumulation, innovation and catching-up: an extended cumulative growth model." Cambridge Journal of Economics, 26(2), p. 201-2016.

Marques, A. e Fochezatto, A. (2006) "Importância do canal do custo na transmissão dos efeitos da taxa de juros sobre os preços na economia brasileira, 1994-2005."11Encontro Nacional de Economia Política, Vitória, Disponível em https://goo.gl/9PS3JB. Acesso em março de 2017.

Mendonça, H. (2004) "Mensurando a credibilidade do regime de metas inflacionárias no Brasil." Revista de Economia política, 24(3), 95, p. 344-350.

Mendonça, H. (2005) "Metas para inflação e variáveis macroeconômicas: uma avaliação empírica." 33 Encontro Nacional de Economia da ANPEC, Natal. Disponível em https://goo.gl/zMjmhr>. Acessado em 01/03/2017.

Mendonça, H. (2007) "Metas de inflação e taxa de juros no Brasil: uma análise do efeito dos preços livres e administrados." Revista de Economia Política, 27(3), 107, p. 431-451.

Mendonça, H., de Dezordi, L. e Curado, M. (2009) "A Determinação da Taxa de Juros em um Economia sob Metas de Inflação: o caso brasileiro." In: J. L. Oreiro, L. F. de Paula e R. Sobreira (eds.) Política Monetária, Bancos Centrais e Metas de Inflação: teoria e experiência brasileira, Rio de Janeiro: Editora FGV, 1a ed., p. 165-186

Meyer, L. H. (2001) Does Money Matter. Federal Reserve Bank of St. Louis Review Working Paper, $\mathrm{n} 083$

Minella, A., Freitas, P., Goldfajn, I. e Muinhos, M. (2003) "Inflation targeting in Brazil: constructing credibility under exchange rate volatility."Journal of international Money and Finance, 22(7), p. 1015-1040.

Minsky, H. (1986) Stabilizing an Unstable Economy. New Haven: Yale University Press.

Minsky, H. (1991) "The Financial Instability Hypothesis: a Clarification." In: M. Feldstein (Org.) The Risk of Economic Crisis. Chicago: The University of Chicago Press.

Modenesi, A. e Araújo, E. (2013) "Price stability under inflation targeting in Brazil: empirical analysis of the mechanism of transmission of the monetary policy based on a VAR model, 2000-2008." Investigación Económica, 72(283), p. 99-133.

Modenesi, A. (2005) Regimes monetários: teoria e a experiência do real. Barueri: Editora Manole Ltda. 
Nier, E., Sedik, T. e Mondino, T. (2014) "Gross Private Capital Flows to Emerging Markets: Can the Global Financial Cycle Be Tamed?"International Monetary Fund (IMF) Working Papern. 14/196.

Nogueira Jr., R. (2006) "Inflation targeting, exchange rate pass-through and "Fear of Floating"."Economia Aplicada, 11(2), p. 189-208.

Oreiro, J. (2012) "Novo-desenvolvimentismo, crescimento econômico e regimes de política macroeconômica." Estudos avançados, 26(75), p. 29-40.

Oreiro, J., Nakabashi, L. e Souza, G. (2010) "A economia brasileira puxada pela demanda agregada." Revista de Economia Política, 30(4), p. 581-603.

Pasricha, G., Falagiarda, M., Bijsterbosch, M. e Aizenman, J. (2015) "Domestic and Multilateral Effects of Capital Controls in Emerging Markets."NBER Working Paper n. 20822.

Pesaran, M. e Shin, Y. (1998) "Generalized impulse response analysis in linear multivariate models." Economics Letters, 58(1), p. 17-29.

Rey, H. (2013) "Dilemma not Trilemma: The Global Financial Cycle and Monetary Policy Independence", Federal Reserve Bank of Kansas City Working Paper. Disponível em $<$ https://goo.gl/xmXUad>. Acessado em 01/05/2017, p. 285-333.

Sicsú, J. (2002). "Expectativas inflacionárias no regime de metas de inflação: uma análise preliminar do caso brasileiro." Economia aplicada, 6(4), p.703-711.

Sicsú, J. (2003) "Políticas não-monetárias de controle da inflação: uma proposta póskeynesiana." Análise Econômica, 21(39).

Sims, C. (1992) "Interpreting the macroeconomic time series facts: The effects of monetary policy."European Economic Review, 36(5), p. 975-1000.

Squeff, G. (2009) Repasse cambial 'reverso': uma avaliação sobre a relação entre a taxa de câmbio e IPCA no Brasil (1999-2007). Dissertação de Mestrado, Universidade Estadual do Rio de Janeiro.

Staiger, D., Stock, J. e Watson, M. (1997) "The NAIRU, unemployment and monetary policy."The Journal of Economic Perspectives, 11(1), p. 33-49.

Svensson, L. (2000) "How Should Monetary Policy Be Conducted in an Era of Price Stability?" NBER Working Paper Series, no 7516.

Tsay, R. (2005) Analysis of Financial Time Series. New Jersey: John Wiley \& Sons.

Walsh, C. (2003) Monetary Theory and Policy. Cambridge (Ma): MIT Press. 